\title{
Docência Compartilhada Integrada: Bases para Proposta de Arquitetura Pedagógica para Cursos a Distância
}

\author{
Renata Luiza da Costa ${ }^{1}$ \\ ${ }^{1}$ Departamento de Informática - Instituto Federal de Educação, Ciência e Tecnologia de \\ Goiás (IFG) \\ renata.costa@ifg.edu.br

\begin{abstract}
This paper proposes a pedagogical architecture for distance courses. This proposal was organized from research conducted with distance technical courses [Costa 2015] and concepts: pedagogical-didactic mediation [Lenoir 2014], integral formation [Vygotsky 1931] - recommended for all levels of basic education in Brazil regardless of how it is offered - and the concept of integrated shared teaching, expression explained in this article.
\end{abstract} \\ Resumo. Este artigo apresenta uma proposta de arquitetura pedagógica para \\ cursos a distância. Tal proposta foi organizada a partir de pesquisa \\ desenvolvida com cursos técnicos a distância [Costa 2015] e dos conceitos: \\ mediação pedagógico-didática [Lenoir 2014], formação integral [Vygotsky \\ 1931] - preconizada para todos os níveis da educação básica no Brasil \\ independentemente da forma como é ofertada - e o conceito de docência \\ compartilhada integrada, expressão explicada neste artigo.
}

\section{Introdução}

No Brasil, desde 2002, a Educação Profissional Técnica vem sendo foco das políticas do governo nacional e, por essa razão, tem sido expandida sua oferta por todo país. Apesar das políticas de estímulo à expansão, o Brasil é um país de grandes dimensões e diferenças geográficas e por isso ainda há muitas regiões sem escolas de educação profissional pública, gratuita e de qualidade. Por essa razão, desde 2007, foi regulamentada a oferta de educação técnica a distância por meio da criação do Programa Rede e-Tec Brasil [Brasil 2007].

Nos últimos anos, os cursos técnicos a distância tiveram crescimento em sua oferta de $8 \%$ ao ano e ainda tem muita perspectiva crescimento considerando as necessidades de desenvolvimento regional no país e de acessibilidade à educação profissional gratuita [ABED 2015]. Apesar disso, desde os primeiros cursos a partir de 2008, esses cursos técnicos a distância não passaram por avaliação pedagógica que analise a qualidade das aprendizagens, tanto em nível técnico como na formação integral preconizada nos documentos brasileiros.

Além disso, há poucas pesquisas sobre o tema no Brasil. $\mathrm{O}$ foco das pesquisas no campo da Educação Profissional Técnica tem sido, predominantemente, político. Por essa razão, foi desenvolvida pesquisa, de cunho pedagógico, junto a três escolas profissionais da rede federal culminando na proposta aqui apresentada: a docência compartilhada integrada.

Tendo sido verificado pelos dados da pesquisa de Costa (2015) frágeis propostas pedagógicas, principalmente para a dimensão da formação técnica feita a distância, 
V Congresso Brasileiro de Informática na Educação (CBIE 2016)

Anais dos Workshops do V Congresso Brasileiro de Informática na Educação (CBIE 2016)

investimos num amplo estudo bibliográfico que, concatenado a tais dados nos permitiu organizar a proposta aqui apresentada visando a atender à formação integral e à formação técnica com qualidade. Tal modelo, chamado por nós de docência compartilhada integrada, será fundamentado e explicado nas páginas que seguem.

\section{Concepções e diretrizes para a Educação Profissional Técnica}

O documento Concepções e Diretrizes para os Novos Institutos Federais traz um conteúdo com um sentido de educação emancipatória de modo que a educação profissional dessas escolas tenha "estreito compromisso com o desenvolvimento integral do cidadão trabalhador" [Brasil 2010]. Para além da formação profissional técnica, são estabelecidos os seguintes objetivos:

A educação para o trabalho nessa perspectiva entende-se como potencializadora do ser humano, enquanto integralidade, no desenvolvimento de sua capacidade de gerar conhecimentos a partir de uma prática interativa com a realidade, na perspectiva de sua emancipação. [...] Com essa dimensão, seria equivocado e reducionista, pois, imaginar que a necessidade da formação para ocupar os postos de trabalho seja a razão exclusiva e definidora para a educação profissional. [Id. p. 35]

Em outro documento, Diretrizes Curriculares Nacionais para Educação Profissional Técnica [Brasil 2012], a ideia da formação integral por meio das oportunidades de educação profissional é endossada:

I- A relação e articulação entre a formação desenvolvida no Ensino Médio e a preparação para o exercício das profisssões técnicas, visando à formação integral do estudante; [...] III - trabalho assumido como princípio educativo, tendo sua integração com a ciência, a tecnologia e a cultura como base da proposta político-pedagógica e do desenvolvimento curricular; VI - [...] a indissociabilidade entre teoria e prática no processo de ensino-aprendizagem; [Id. p. 2].

Verifica-se nessas orientações uma perspectiva de educação profissional, independentemente se é presencial ou a distância, que indica necessidades mais intensas, conforme veremos em Lenoir (2014), de mediação docente didática com a finalidade de articular a formação profissional com as demais dimensões comportamentais de formação dos indivíduos. Nesse sentido, apresentam-se necessárias estruturas mais ampliadas que integrem ciência, cultura e tecnologia, visando capacitar o estudante para o domínio intelectual das tecnologias e geração de conhecimento. Nessa condição, o docente tem espaço importante em assumir um trabalho pedagógico criterioso que implica preparação, organização e monitoramento de atividades de ensino e estudo e a organização em função do desenvolvimento cognitivo, afetivo e moral dos alunos.

\section{O desenvolvimento humano integral e sua relação com a mediação docente}

De acordo com Vygotsky (1931), o desenvolvimento humano é sociohistorico e cultural conforme a inserção e participação nas práticas sociais e, especialmente, nos processos educacionais formais que agem com intencionalidade sobre a formação do indivíduo. Nessa intencionalidade dos processos de ensino, o que faz especial diferença para o 
V Congresso Brasileiro de Informática na Educação (CBIE 2016)

Anais dos Workshops do V Congresso Brasileiro de Informática na Educação (CBIE 2016)

desenvolvimento humano, conforme o autor explica, é a mediação docente porque não é espontânea, mas tem objetivos formativos explícitos.

O desenvolvimento integral do indivíduo é caracterizado pelo desenvolvimento articulado das capacidades intelectuais e comportamentais, ou seja, da aquisição de conhecimentos técnico-científicos e suas capacidades cognoscitivas correspondentes e atitudinais, conforme a qualidade da participação nas atividades orientadas. Da articulação necessária para o desenvolvimento humano, quem tem conhecimento e autoridade profissional para fazê-la é o professor, o profissional da educação.

Vygotsky [Ibid. p. 19 - tradução minha] explica que "[...] a cultura origina formas específicas de conduta, modifica a atividade das funções psíquicas, edifica novos níveis no sistema de comportamento humano em desenvolvimento" e essa edificação só se concretiza por meio de um processo de ensino "vivo", que "[...] deve ser objeto de um verdadeiro estudo científico" [Ibid. p. 212] pelo aluno. Por essa razão, é que a atuação do professor, conforme sua mediação, desde o planejamento do ensino passando pela organização das atividades e seu acompanhamento junto do aluno, faz diferença no desenvolvimento do aluno.

As pesquisas da Escola de Vygotsky mostram que a inteligência não é nata e deixa de alcançar níveis superiores ao manter-se apenas com o conhecimento cotidiano dos alunos ou quando mantém-se na busca espontânea dos interesses dos alunos.

Nessa linha, na perspectiva da Teoria Histórico-Cultural de Vyotsky, o professor deve preparar um ensino em que o aluno participe de modo investigativo, conforme as características lógico-investigativas de cada área [Davydov 1988], e fazer intervenções que regulem a aprendizagem dos alunos cada vez mais para níveis superiores.

Isso quer dizer que as atividades que fazem parte do processo de ensinoaprendizagem devem ser problematizadas, contextualizadas a partir de exemplos reais, incluindo, desde o início, formas de atividades em que os alunos possam pesquisar, analisar, supor, simular, organizar e registrar seus raciocínios, dentre outras ações de verificação e exposição, para que eles mesmos possam ir construindo os conceitos. Além disso, as atividades devem ocorrer começando pelas coletivas até as individuais, da pesquisa espontânea para as ações orientadas, até que os objetivos de aprendizagem sejam alcançados.

No decorrer do desenvolvimento das atividades devem perpassar indagações suscitadoras de reflexões que vão orientando as ações com o objeto de estudo. $\mathrm{O}$ acompanhamento do professor deve ser, portanto, para além de apresentar conteúdo, mas para monitorar e intervir no sentido de direcionar o aluno nas transformações com o objeto até que se aproprie dele e seja autônomo naquela atividade. Ao intervir com questionamentos e/ou com reorganização das tarefas, o objetivo do ensino deve ser despertar descobertas e direcionar a busca do aluno para que ele mesmo vá construindo as relações necessárias para domínio do conceito. Desse modo, a mediação docente não é uma ação previamente fixada, embora seja planejada. Ela parte de um planejamento que deve ser flexível para que, na medida em que se acompanha o aluno e verifica sua compreensão, o professor propõe atividades para superar as lacunas e dificuldades diagnosticadas até os alunos se apropriarem do conhecimento.

A mediação didática é um processo de monitoramento e intervenção pedagógicocognitiva composta por ações, observações e falas intencionais do professor, dependente das expressões dos estudantes para que se possa ter melhor êxito. Por isso, é preciso 
V Congresso Brasileiro de Informática na Educação (CBIE 2016)

Anais dos Workshops do V Congresso Brasileiro de Informática na Educação (CBIE 2016)

garantir condições de expressão tanto por parte dos alunos quanto dos professores.

De acordo com Lenoir (2014), a aprendizagem é indissociável da relação de mediação e implica uma interatividade prática e reguladora entre os sujeitos aprendentes, o objeto de estudo, as normas em geral e um interventor socialmente investido de mandato, o professor. Para este autor (Ib.), não é possível alcançar níveis tão superiores ou articular uma formação integral sem uma ação docente especificamente planejada para tal. $\mathrm{O}$ desenvolvimento cognitivo é um processo guiado que, para efeitos de emancipação intelectual, “[...] requer a mediação pedagógicodidática, sem a qual não se pode desencadear uma relação de objetivação cognitiva em caráter científico" [Ibid. p. 203], e consequentemente, a formação integral do indivíduo.

\section{Tipos de mediação docente}

Segundo Lenoir (2014), a mediação docente pode ser do tipo instrumental ou pedagógico-didática.

A mediação docente do tipo instrumental é assim caracterizada por Lenoir (2014) devido a preponderância de ações restritas à resolução de conflitos operacionais, de compartilhamento de recursos tecno-didáticos e procedimentos de negociação, em detrimento de uma atividade docente reguladora e auxiliadora focada na aprendizagem do aluno.

Essa perspectiva de mediação docente trata os problemas surgidos no processo de ensino-aprendizagem como problemas de incapacidade intelectual ou falta de dedicação do aluno, na medida em que o professor não se responsabiliza pelo ensino. Considera todo caso fora do comum ou quando o aluno não consegue aprender como algum problema do aluno, algo não relacionado com a relação de ensino-aprendizagem sem influências da forma como o professor atua. integral:

Já a mediação docente pedagógico-didática guia o aluno para o desenvolvimento

Ao contrário da concepção instrumental (a mais comum), a concepção dialética se inscreve numa abordagem histórico-filosófica, o que quer dizer que ela repousa sobre o postulado ontológico de que todo ser humano se constrói coletivamente construindo com o outro a realidade no tempo e no espaço e visa alguma forma de emancipação social. [Lenoir 2014, p. 62-63 - tradução minha, grifos no original]

Lenoir (2014) explica que o papel da mediação pedagógico-didática compreende, para além do desenvolvimento cognitivo e moral. Ela inclui a dimensão afetiva relacionada a importância do papel social dos sujeitos envolvidos no processo de ensino-aprendizagem e inseridos numa sociedade. Nessa perspectiva, este autor chama de "poderoso mediador" (op. cit.), o desejo. O desejo de cada um pelo saber é nascido do desejo expressado e compartilhado socialmente e é renovado em relação ao reconhecimento social, tendo nisso, o professor um papel primordial:

Um sujeito aprendiz, enquanto empreendedor de seu percurso escolar, não estuda por amor às disciplinas escolares. $\mathrm{O}$ motor do processo de aprendizagem se encontra inicialmente, num poderoso mediador que é o desejo do desejo do outro. [...] Mas este surgimento (o do desejo) não é nem de natureza espontânea e nem resultado de uma conversão interna qualquer que realizaria um sujeito de maneira autônoma. Ele é devido aos encontros com alguns professores fora do comum, os quais seriam os portadores do desejo do saber. [Ibid. p. 33 - tradução minha] 
Nessa lógica, a concretização da mediação pedagógico-didática em processos educacionais formais requer, necessariamente, condições que permitam a construção de relações sociais pedagógicas baseadas em atividades com diálogos, reflexão, manipulação e produções coletivas e individuais. Tal mediação não se resolve polarizando na socialização ou na organização de recursos técnico-didáticos. A mediação pedagógico-didática corresponde a uma rede de ações integradoras e reguladoras que ocorrem pelo caminho da relação social pedagógica, intencionalmente planejada com conteúdos científicos em atividades com caráter científico, a fím de conduzir os alunos a um articulado desenvolvimento intelectual, afetivo e moral.

\section{Percepções dos alunos, professores e tutores atuantes na educação técnica a distância}

A pesquisa realizada por Costa (2015) teve como estudo de campo três escolas da rede federal, sendo dois institutos federais e um CEFET. Foi uma pesquisa qualitativa em que, além de analisar as aulas (incluindo atividades e avaliações) online e atendimentos nos polos, foram entrevistados coordenadores (7), professores (7), tutores (5) e alunos (41).

Com relação aos polos, os quais deveriam apoiar e complementar as ações pedagógicas e administrativas realizadas online, observou-se que eles atendem as demandas dos alunos apenas no que diz respeito a serviços administrativos. Com relação ao atendimento pedagógico de auxílio à resolução das atividades e à realização de aulas específicas de práticas profissionais para complementar a formação, o atendimento é precário e a razão mencionada é o fato dos tutores não terem conhecimento específico das disciplinas. Eles são contratados apenas pelo requisito mínimo de ter Ensino Médio completo e devem ajudar os alunos em diferentes disciplinas. Mesmo quando são professores, não atendem conforme sua área de formação.

Com relação aos projetos dos cursos, eles eliminaram as atividades complementares do tipo sociocultural e científica, visitas-técnicas, aulas de campo, aulas de prática laboratorial e disciplinas de formação socioambiental e humana. Um dos cursos (técnico em Informática) eliminou até o estágio, ficando o aluno sem nenhum tipo de contato com prática profissional.

As turmas encontradas para estes cursos eram, em média, de 50 alunos por polo, o que corresponde a pelo menos duzentos e cinquenta alunos por turma por professor.

Apenas um dos cursos previa um encontro semanal no polo para ter aula por videoconferencia com o professor da disciplina. Esse mesmo curso também oferecia chat semanal com o próprio professor. Esse curso foi o único a não ter evasão maior que $25 \%$. Os demais, todos apresentavam evasão de 36 a 49\%.

Nos cursos que não previam encontros online com nenhuma regularidade, os alunos só falavam no ambiente online com o professor se enviassem alguma mensagem com dúvida e, ainda assim, algumas não eram respondidas. Foi unânime entre os alunos que os professores e tutores demoram muito a responder, os tutores não sabem a matéria e eles se sentem ignorados.

Os alunos também afirmaram que são essenciais atendimento adequado pelo 
professor, mais aulas práticas e atendimentos em tempo hábil, pois também disseram que, apesar de serem adultos, eles buscam informação porque não a encontraram, ou seja, não conseguem ainda fazer tudo sozinhos e precisam da ajuda de quem sabe mais, principalmente nas disciplinas técnicas.

Os professores apontaram a quantidade excessiva de alunos por turma, a tutoria fora da área de formação e a organização em módulos, como veementes problemas que os fazem mudar o planejamento da aula para atividades apenas objetivas, individuais e distantes das práticas profissionais.

Alguns tutores afirmaram se sentir inúteis porque não conseguem ajudar os alunos na resolução de exercícios e os professores demoram muito para responder suas dúvidas de modo que possam transferir as respostas aos alunos. Tanto os professores quanto os tutores afirmaram nas entrevistas que, se os tutores fossem contratados por área, eles poderiam ajudar muito mais na aprendizagem dos alunos como também nas correções e acompanhamento online e presencial dos mesmos, sendo desnecessário os professores mudarem seu planejamento para restritas atividades.

A partir do conceito de mediação pedagógico-didática de Lenoir (2014), pode-se afirmar que a restrição das atividades sempre em modo objetivo e o não acompanhamento e regulação das atividades por um profissional investido de conhecimento não sustentam um tipo de atividade investigativa que desenvolve capacidade de reflexão e análise para o desenvolvimento cognitivo dos estudantes. Trata-se apenas de ler o material disponibilizado, memorizar e responder os questionários. Há um intenso empobrecimento do processo de ensino-aprendizagem que, associado à eliminação das atividades práticas, não prejudica só a formação integral dos alunos, mas também produz uma formação técnica vulnerável.

Além disso, com relação ao papel do desejo para a motivação do aluno, Vygotsky (1931) e Lenoir (2014) explicam que ao desconsiderar a dimensão afetiva das relações sociais que ocorrem por meio das diversas formas de comunicação, a vontade e o desejo são subestimados, o que pode explicar índices de evasão tão altos. Embora adultos, o perfil do alunado da educação profissional técnica é de pessoas das classes baixas, muitos sem estudar há muito tempo, trabalhadores mães e pais de família. Essa conjugação de fatores inviabiliza a estruturas em que se predomina o uso de recursos tecnolíógicos, mediação instrumental e pouco contato com um professor que sabe a disciplina.

Esses depoimentos indicam a ocorrência de mediação docente instrumental. Por outro lado, evidenciam que a mediação docente encontrada, mediada pelas condições físicas e pedagógicas de trabalho, especialmente a quantidade de alunos e o tutor sem formação, não poderia culminar em situação diferente. $\mathrm{O}$ próprio modelo implantado não cria condições de trabalho pedagógico efetivo pelos professores nem em ambiente online e nem nos polos [Costa 2015]. A relação tutor-professor que era para ser complementar, termina com indiferença. O modelo de formação técnica a distância vigente no Brasil, portanto, não corresponde aos objetivos preconizados nos documentos oficiais de formação integral.

Todavia, destaca-se que alguns estudantes afirmaram que gostam muito dos cursos e destacaram pontos relevantes como ter atendimento com professor que domine o assunto, online e presencial, ter o mesmo conteúdo em diferentes mídias, ter exercícios resolvidos em videoaula com o próprio professor - melhora o contato com o 
V Congresso Brasileiro de Informática na Educação (CBIE 2016)

Anais dos Workshops do V Congresso Brasileiro de Informática na Educação (CBIE 2016)

professor e então influencia a relação cognitivo-afetiva, e ter aulas práticas no que diz respeito especialmente à formação técnica. Por meio dessas características, observamos que em algumas disciplinas os resultados eram melhores e os alunos estavam mais satisfeitos, usando até alguns professores como exemplo. Isso comprova que é possível uma mediação pedagógico-didática online com qualidade, o que pode ser endossado pelas pesquisas de Vygotsky e Luria (2007) que explicam que a geração de significados e sentidos nas relações humanas podem vir de uma ampla variedade de operações com signos:

\begin{abstract}
Por uma parte, um estudo mais amplo de outras formas de atividade simbólica infantil nos mostra que não só a fala, sim todas as operações relacionadas com o uso de signos em toda a sua variedade e condições mostram o mesmo padrão evolutivo, a mesma organização e idêntico funcionamento que a fala. [...] Reconhecer esta importância fundamental dos signos no desenvolvimento das funções psíquicas superiores tem uma consequência lógica: devemos incluir no sistema de categorias psicológicas aquelas formas psicológicas externas de atividade - como a fala, a leitura, a escrita, o cálculo ou o desenho... O comportamento do homem é o produto do desenvolvimento de um sistema mais amplo de vínculos e relações sociais, de formas coletivas de conduta e de cooperação social. [Vygotsky 2007 p. 49, 50 e 51 - tradução minha]
\end{abstract}

Torna-se, portanto, imprescindível, repensar o modelo vigente, pois os cursos técnicos são necessários tanto para o desenvolvimento regional, refletindo no desenvolvimento do país, quanto como oportunidade de qualificação para o povo.

\title{
6. A docência compartilhada integrada (DCI)
}

A respeito das estruturas pedagógicas apresentadas para os cursos técnicos a distância pesquisados, ficou exposto que não correspondem com a formação integral preconizada nos documentos oficiais e até a formação técnica é questionável. Por outro lado, tornouse visível, também, possibilidades de desenvolvimento de mediação docente pedagógico-didática em ambiente online e a necessidade da articulação com atividades práticas presenciais, ou seja, é necessário explorar melhor os polos.

Em que pese o potencial tecnológico comunicacional das tecnologias de informação e comunicação (TIC), para seu uso pedagógico elas são dependentes da postura pedagógica do professor que também depende de formação e das condições de trabalho [Libâneo 2011]. As TIC não conseguem, por si só, atender às necessidades humanas que permeiam o processo de ensino-aprendizagem. Por isso, foram relevados tantos sentimentos negativos no que diz respeito ao acompanhamento e atendimento dos alunos. Isso permite afirmar que as estruturas curriculares desses cursos a distância, ainda que prevejam esparsos encontros presenciais, devem contemplar regularidade em encontros online, tendo em vista que existem necessidades cognitivo-afetivas que só podem ser mitigadas a partir de relações sociais pedagógicas regulares. Essas necessidades são naturais dos processos de ensino-aprendizagem e a resposta a elas vai alimentar o desejo por aprender e permanecer no curso.

Entendemos que a tutoria da forma em que está instaurada atualmente nas estruturas apresentadas não atende às demandas dos alunos, pois eles precisam de professores com formação na área tanto para dúvidas demandadas online quanto para atividades presenciais no polo. Além disso, embora os documentos nacionais tenham 
posto o termo tutor como se não tratasse de atividades docentes, as pesquisas (TONETTI, 2012; COSTA, 2015) mostram que eles exercem atividades de professor. Por essas razões, fica clara a necessidade de professor da área, não de uma tutoria apenas de aconselhamento. Essa mudança de nomenclatura é artifício para precarização do trabalho docente e, consequentemente, da sua remuneração. A inexistência de um acompanhamento com domínio na área leva ao retardo no atendimento online, desmotivação dos alunos, à subutilização dos polos como complementação do processo de ensino-aprendizagem com atividades práticas e técnicas e, consequentemente, formação insuficiente para os alunos. Portanto, é preciso uma estrutura de multidocência compartilhada e distribuída entre professores para todo tipo de acompanhamento do aluno. Em que pese os estudos de Mill e Fidalgo (2007) com a proposta da polidocência, é preciso ressaltar que neste conceito são destacados os papéis de diversos profissionais que contribuem com o estudo dos alunos e mantém a existência do tutor e a estrutura hierárquica entre esses profissionais variados.

A partir dessas considerações, propõe-se uma estrutura que chamamos de docência compartilhada integrada: uma estrutura não-hierárquica, mas distribuída e colaborativa entre professores para que os atendimentos online e presencial não concorram entre si, mas se complementem visando uma formação de excelência. Nessa estrutura, o professor é o responsável pela disciplina do planejamento ao atendimento online e presencial no seu polo, e professores em cada polo com formações também área complementam o trabalho do professor principal com a finalidade de atenderem com qualidade as dúvidas dos alunos que procuram o polo mas, essencialmente, propor atividades práticas e grupos de estudos voltados para a disicplina. Ou seja, não se trata de dividir tarefas, mas de compartilhar o conhecimento de cada professor para que haja atendimentos com qualidade, tanto em conteúdo como em tempo de resposta, tanto online quanto no polo. Assim, ao mesmo tempo que se compartilha as atividades da docência, elas são integradas e orientadas pelo professor principal enriquecendo o que ocorre online e o que ocorre nos polos para fins de aprendizagem integral.

Compartilhada refere-se à necessidade de responsabilização conjunta na docência realizada de maneira distribuída entre profissionais com conhecimento e autoridade profissional de professor. Detectamos que é preciso compartilhar a responsabilidade do ensino entre um professor que atenda online e outro presencial, de modo integrador, ou seja, não se trata de dividir tarefas, mas de ambos complementarem o acompanhamento pedagógico de um e de outro com relação ao processo de ensinoaprendizagem que ocorre a distância a fim de ajudar o aluno a aprender e ter experiências ricas de prática profissional em laboratórios, o que só pode ser feito em locais específicos orientados por professor com conhecimento da área.

$\mathrm{Na}$ docência compatilhada integrada, as atividades do professor vinculado ao polo são compostas por um conjunto de atividades presenciais e também auxílio e acompanhamento no Ambiente Virtual de Ensino-Aprendizagem (AVEA), conforme sua área específica, de modo que possa ter acesso aos feedbacks dos alunos para repensar suas atividades presenciais e suas intervenções online.

Com a docência compartilhada integrada, o professor principal é o responsável pela preparação do plano de ensino, atividades, projetos e avaliações de modo a dar a direção ao ensino em função dos objetivos. Todavia, esse planejamento é coletivo com os demais, desde o início, sob a orientação do professor principal. O compartilhamento das responsabilidades é mais visível no monitoramento e regulação das atividades dos 
V Congresso Brasileiro de Informática na Educação (CBIE 2016)

Anais dos Workshops do V Congresso Brasileiro de Informática na Educação (CBIE 2016)

alunos. Assim, cada professor de polo pode e deve responder e questionar aos alunos dentro do AVEA e no seu polo.

\section{Referências}

ABED (2015) "Censo EaD.br”: Relatório Analítico da Aprendizagem a Distância no Brasil 2014. Curitiba: Ibpex.

Costa, R. L. (2015) "Educação profissional técnica de nível médio a distância": estudo da mediação docente no modelo da Rede e-Tec Brasil na rede federal. Tese (doutorado) - PUC - GO, Pós-Graduação Stricto Sensu em Educação. Goiânia.

Brasil (2007) "Decreto 6.301 de 12 de dezembro". Institui a Escola Técnica Aberta do Brasil: e-Tec.

Brasil (2010) "Um Novo Modelo de Educação Profissional e Tecnológica”: Concepções e Diretrizes.

Brasil (2012) "Resolução $\mathrm{n}^{0}$ 6, de 20 de setembro de 2012". Define Diretrizes Curriculares Nacionais para a Educação Profissional Técnica de Nível Médio.

Davydov, V. V. (1988) "Problemas do Ensino Desenvolvimental": A Experiência da Pesquisa Teórica e Experimental na Psicologia. Textos publicados na Revista Soviet Education, August/VOL XXX, $\mathrm{N}^{\circ}$ 8, sob o título "Problems of Developmental Teaching. Tradução de José Carlos Libâneo e de Raquel A. M. da M. Freitas.

Lenoir, Y. (2014) "Les médiations au cœur des pratiques d'enseignement-apprentissage: une approche dialectique": Des fondements à leur actualisation en classe éléments pour une théorie de l'intervention éducative. Longueuil: Groupéditions éditeurs.

Libâneo, J. C. (2002) "Didática: Velhos e novos temas". Edição do Autor.

Mill, D.; Fidalgo, F. (2007) Sobre tutoria virtual na educação a distância: caracterizando o teletrabalho docente. In: Virtual Educa Brasil.

Tonetti, F. A. (2012) "Tutor é Professor: Algumas Considerações Sobre o Trabalho Docente na Educação a Distância”. In: Simpósio Internacional de Educação a Distância. V. 1, n. 1.

Vygotsky, L. S. (1931) “Historia del Desarrollo de las Funciones Psíquicas Superiores”. Obras Escogidas Tomo III. Comisión editorial para la edición en lengua rusa.

Vygotsky. L. e Luria, A. (2007) "El instrumento y el signo en el desarrollo del niño". Edición a cargo de Pablo del Río y Amelia Álvarez. Fundación Infancia y Aprendizaje. 